\title{
Imaging pore space in tight gas sandstone reservoir: insights from broad ion beam cross-sectioning
}

\author{
G. Desbois ${ }^{1, a .}$, F. Enzmann ${ }^{2}$, J.L. Urai ${ }^{1}$, C. Baerle ${ }^{3}$, P.A. Kukla ${ }^{4}$ and J. Konstanty ${ }^{5}$ \\ ${ }^{1}$ Structural geology, Tectonics and Geomechanics, RWTH Aachen University, Lochnerstrasse 4-20, D-52056 Aachen, Germany \\ ${ }^{2}$ Institut für Geowissenschaften, Johannes Gutenberg-Universität Mainz, Mainz, Germany \\ ${ }^{3}$ Wintershall Holding AG, Erdölwerke Barnstorf, Rechterner Straße 2, 49406 Barnstorf, Germany \\ ${ }^{4}$ Geological Institute, RWTH Aachen University, Wüllnerstr. 2, D-52056 Aachen, Germany \\ ${ }^{5}$ Wintershall Holding AG, Friedrich-Ebert-Straße 160, 34119 Kassel, Germany
}

\begin{abstract}
Monetization of tight gas reservoirs, which contain significant gas reserves world-wide, represents a challenge for the entire oil and gas industry. The development of new technologies to enhance tight gas reservoir productivity is strongly dependent on an improved understanding of the rock properties and especially the pore framework. Numerous methods are now available to characterize sandstone cores. However, the pore space characterization at pore scale remains difficult due to the fine pore size and delicate sample preparation, and has thus been mostly indirectly inferred until now. Here we propose a new method of ultra high-resolution petrography combining high resolution SEM and argon ion beam cross sectioning (BIB, Broad Ion Beam) which prepares smooth and damage free surfaces. We demonstrate this method using the example of Permian (Rotliegend) age tight gas sandstone core samples. The combination of Ar-beam cross-sectioning facility and high-resolution SEM imaging has the potential to result in a step change in the understanding of pore geometries, in terms of its morphology, spatial distribution and evolution based on the generation of unprecedented image quality and resolution enhancing the predictive reliability of image analysis.
\end{abstract}

\section{Introduction}

With the decline of production and increase in demand for fossil fuel, producing gas commercially from unconventional sources remains a great challenge. Tight gas reservoirs, with their low permeability and low porosity, have recently become a target for geophysicists and geologists as they contain potentially huge natural source for the recovery of hydrocarbons previously deemed uncommercial. Tight gas reservoirs are found throughout the world and occur in most of the common types of reservoir rocks. Thus, searching for enabling technology for profitable production from tight reservoirs is in the focus of the oil and gas industry: improving recovery factors, lowering operating costs, aiming to capitalize the promising potential of these reservoirs.

The pore space is the reservoir for gas. Consequently, there is an increasing interest in describing and characterizing the porosity and microstructures of these tight gas reservoirs prior to exploration, extraction assisting and development/stimulation plans. However, the pore space characterization remains difficult due to the small pore size, which requires delicate sample preparation. A high-resolution petrographical technique to characterize and understand these tight gas reservoirs lacks to date.

To investigate directly the meso-porosity on a $\mathrm{mm}$ to $\mathrm{nm}$ pore size scale in tight gas reservoirs, SEM imaging is certainly the most direct approach. However, leveraging its full resolution capacity has been hampered by the poor quality of mechanically damaged sample surfaces. Consequently, image analysis and structural-geometrical interpretation has been of limited confidence ([1], [2]).

The recent development of Argon ion source milling tools which allow producing polished cross-sections of exceptionally high quality offer now a new technical milestone of surface preparation suitable for high resolution porosity SEM imaging at nano-scale ([3], [4], [5], $[6])$.

This contribution reports on a study of a Rotliegend sandstone core sample (Bahnsen member from a well in the south of Bremen, Germany) using high resolution SEM combined with argon ion beam cross sectioning (BIB, Broad Ion Beam) to prepare smooth and damage free surfaces. Pictures presented in this paper demonstrate that the combination of these techniques is able to produce unprecedented high quality images of the pore space allowing a new method of investigating porosity in tight gas reservoir drill core samples.

\footnotetext{
a. email: g.desbois@ged.rwth-aachen.de
} 


\section{Samples and methods}

The sample is from a drill core, from approximately $4800 \mathrm{~m}$ depth. The well is located on the southern margin of the North German Basin (forming part of the Central European Basin) in the Arsten Graben, south of Bremen. The Arsten Graben is part of the Northwest German Rotliegend rift system. Compared to other Rotliegend Grabens, the sedimentary fill is made up of lower Rotliegend volcanics at the base of the Graben. Followed by Havel and Dethlingen sediments of mainly aeolian origin, synsedimentary tectonic activity is documented by fanglomeratic sequences. During the deposition of the Hannover Formation, the relief was evened in the north, while in the south the sediments of the Bahnsen and Wustrow Members are still restricted to the Graben elements. We focused our study on a sandstone sample from the upper Rotliegend group, the Bahnsen Member (white/grey bed color, porosity $=9.0 \%$, permeability $=0.2$ $\mathrm{mD}$ ). The sample belongs to units containing aeolian dune or dry sandsheet facies. Characteristic for the analyzed well is, that the more favorable reservoir quality is below the gas-water contact, while in the gas bearing zone, the porosity / permeability is drastically reduced by authigenic minerals. This led to uneconomic flow rates such that the Rotliegend interval was plugged and abandoned.

Firstly, air-dried core samples were sub-sampled by slow cutting with a miniature diamond saw using air as cooling medium.. A flat surface of these samples of about $1 \mathrm{~cm}^{3}$ was cross-sectioned perpendicular to the diamond-cut surface, using a stand-alone argon beam machine (cross-section polisher JEOL SM-09010, [7]) to produce high quality polished cross-sections of about $2 \mathrm{~mm}^{2}$. We used $6 \mathrm{kV}$ voltage achieving currents of about 150-200 nA. This workflow is shown in figure 1 . The polished cross-section was then coated with carbon, suitable for SEM imaging and EDX chemical analysis. The SEM microscope used is a JEOL JSM-7000F with an EDX/EBSD system, (EDAX Pegasus with Genesis 5.2 software). SE images are used for topography investigations while BSE images give information about the nature of phases and details of phases' arrangement. Typically, SEM (in SE and BSE modes) imaging and EDX studies were performed at $15 \mathrm{kV}$ at a working distance of $10 \mathrm{~mm}$. Porosity was statistically evaluated using the PolyLX Matlab toolbox ([8]) from microstructures digitized in Open Jump (open source GIS software) environment from ion-beam-polished-cross-section micrographs.
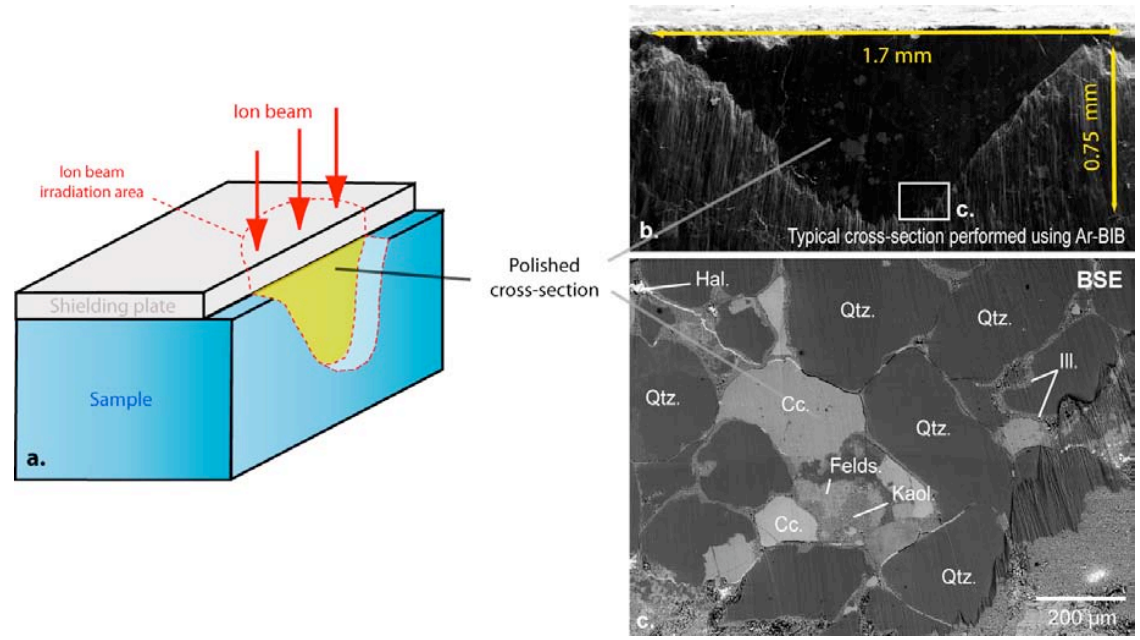

Fig. 1: The principle of BIB cross sectioning. (a) The ion beam irradiates the edge of the sample un-masked by the shielding plate to create mirrorpolished cross-sections suitable for SEM imaging. (b) Overview of a typical cross section obtained using the BIB method (6 KV, 6 hours, $150-200 \mu \mathrm{A})$. (c) Detail from (b) showing the general fabric and mineralogy of the sample: calcite (Cc.), quartz (Qtz.), feldspar (Felds.), halite (Hal.), Illite (Ill.) and Kaolinite (Kaol.)

\section{Results and discussion}

\subsection{Sand framework and mineralogy}

The sample shows typical features of tight, diagenetically altered aeolian sandstone from this part of the Central European Basin ([9]). Optical thin sections and ion beam polished cross-sections (Figures 1.c and 2) show that the grain diameter of the sand is quite homogeneous (average at about $0.2 \mathrm{~mm}$ ). The roundness of grains varies from sub-angular to round with a greater amount of rounded 
grains. Angular grains are rare and were only observed as "floating" fragments in pores cemented by clay matrix (Figure 4.a). The grain fabric is dominated by sutured and concavo-convex contacts possibly evolved by (pressure) dissolution processes and grain rearrangement during compaction. Detrital quartz grains dominate largely the mineralogical composition (from EDX chemical analysis). Other minerals such as calcite, halite and feldspars are also present but subordinate. A significant amount of clay minerals occurs quasi everywhere at grain contacts (Figures 2 and 3). In the vicinity of non-clay minerals, these are predominantly illite while kaolinite is mainly present in the region surrounding the feldspars probably due to the replacement of detrital feldspars. Illite can have two different morphologies: fibrous/hairy or platy. Clay cementations are not post-dated by any other cement. Figures 2 and 3 show that original pores are not simply voids but have complex pore microstructures based on the phyllo-mineral arrangement filling the inter-granular pore space. BIB-prepared cross-sections show details of the morphology of pores down to $10 \mathrm{~nm}$ in size (Figures 2.d and 3).

By studying the relationships and microstructures between the different mineralogical phases, it appears that calcite, halite, feldspars and minor quartz species are involved in the early cementation of the sandstone. As shown in figure 2, quartz cements occur as overgrowth on quartz grains, halite cement fills locally the initial porosity as "pervasive-intrusions", and calcite and feldspars seem to form simply pore-filling cements. Feldspar grains (and much less commonly calcite and quartz) clearly display diagenetic dissolution and alteration.
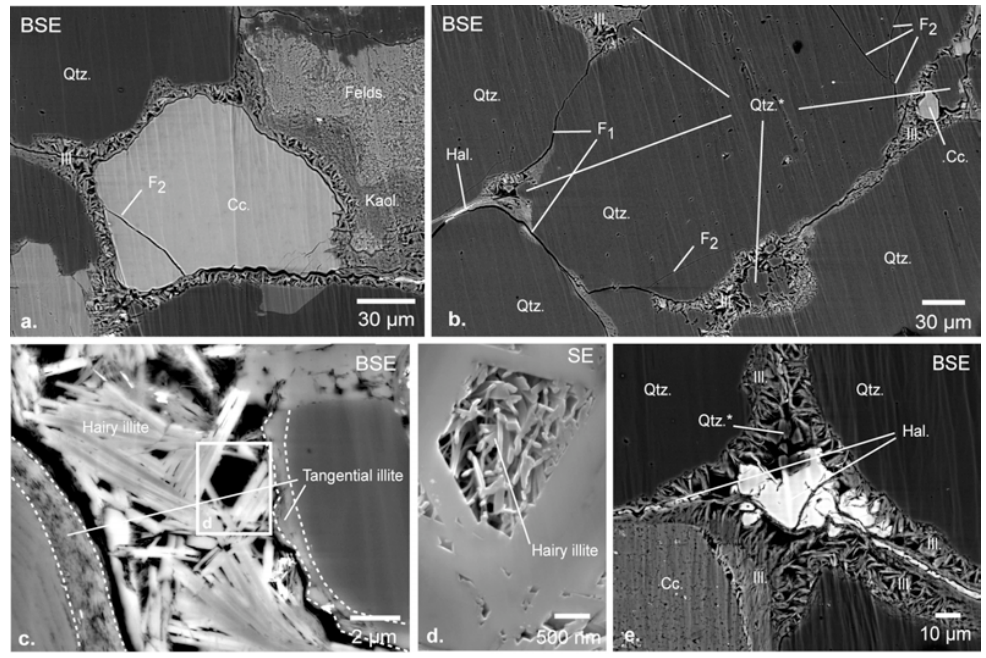

Fig. 2: SEM micrographs (SE and BSE) of typical solid phases revealed by BIB cross sectioning. (a) Typical grain fabric in the studied sample showing the coexistence of un-altered calcite (Cc.), quartz (Qtz.), feldspar (Felds.) and Kaolinite (Kaol). Kaolinite probably originates from alteration of feldspar. Grains are cemented by illite (Ill.) clay mineral. (b) The sample is made of about $60 \%$ of detrital quartz. Quartz has also newly grown into the initial porosity (Qtz*). Calcite, halite (Hal.) are also filling the initial porosity and, as for Qtz*, are pre-dated by illite cementation. (c) Close view of typical narrow grain-grain contact. Grain surfaces are coated with tangential illite, towards the contact center hairy illite dominates. (d) Detail from (c). Quartz-calcite junction filled with quartz fragment (Qtz*.), halite and later illite. Here the calcite grain exhibits porosity.

Though the aim of this contribution is not the inference of diagenetic processes occurring in Rotliegend tight gas reservoir sandstone, we recognized many of the twelve diagenesis types distinguished in [10] and [11]. Following the interpretations in [10] and [11], studied samples give evidence for the following phases in chronological order: Sebkha type (SB), Illite coating type (IC), Hematite type (H), Feldspar leaching type (FL), Kaolinite type (K), Illite meshwork type (IM) and possibly the late quartz type (Q). Thus, our observations are in good agreement with the general model of Rotliegend sandstone diagenesis ([1], [12], [13]), and are interpreted to represent common rock and diagenesis types from the Rotliegend.

\subsection{Pore space characterization}

Non-clay minerals are often coated with illite minerals (Figure 2.c), which are always crystallographically tangential at the surface of the quartz grain, with a compacted fabric and pores close to the limit of SEM resolution. When they are visible, these pores are about 500 $\mathrm{nm}$ long and less than $50 \mathrm{~nm}$ wide, elongated parallel to the adjacent surface of non-clay mineral. Toward the center of cemented regions, illite cement becomes significantly more porous (Figure 2.c,d,e and 3a,b,c). These clay particles have hairy/fibrous morphology and are distributed as a "hugger-mugger meshwork" with a slight tendency to be elongated perpendicular to the tangential illite. Here, 
we distinguished 3 main types of pore morphology (Figure 3.a,c): (1) Type I-elongated pores between similarly oriented clay sheets, (2) Type II - crescent-shaped pores in saddle reefs of folded sheet of clay and (3) Type III - large jagged pores where the density of hairy/fibrous illite is less. Type III pores are typically $>1 \mu \mathrm{m}$, Type II between $1 \mu \mathrm{m}-150 \mathrm{~nm}$ and Type I $<150 \mathrm{~nm}$. Illite cementation seems to be mainly distributed along grain contacts as a 2D interconnected network. Another type of clay cement is formed by kaolinite (Figure 2.a and 3.d,f), which is locally found in the region surrounding the weathered feldspar grains (Figure 2.a). The kaolinite cement has porosity in the range between tangential illite and hairy/fibrous illite. The kaolinite pore morphologies are in the range of the Type I and II as described before for hairy/fibrous illite. However, here the typical pore sizes are significantly smaller: Type II between $400 \mathrm{~nm}$ $-100 \mathrm{~nm}$ and Type $\mathrm{I}<50 \mathrm{~nm}$.
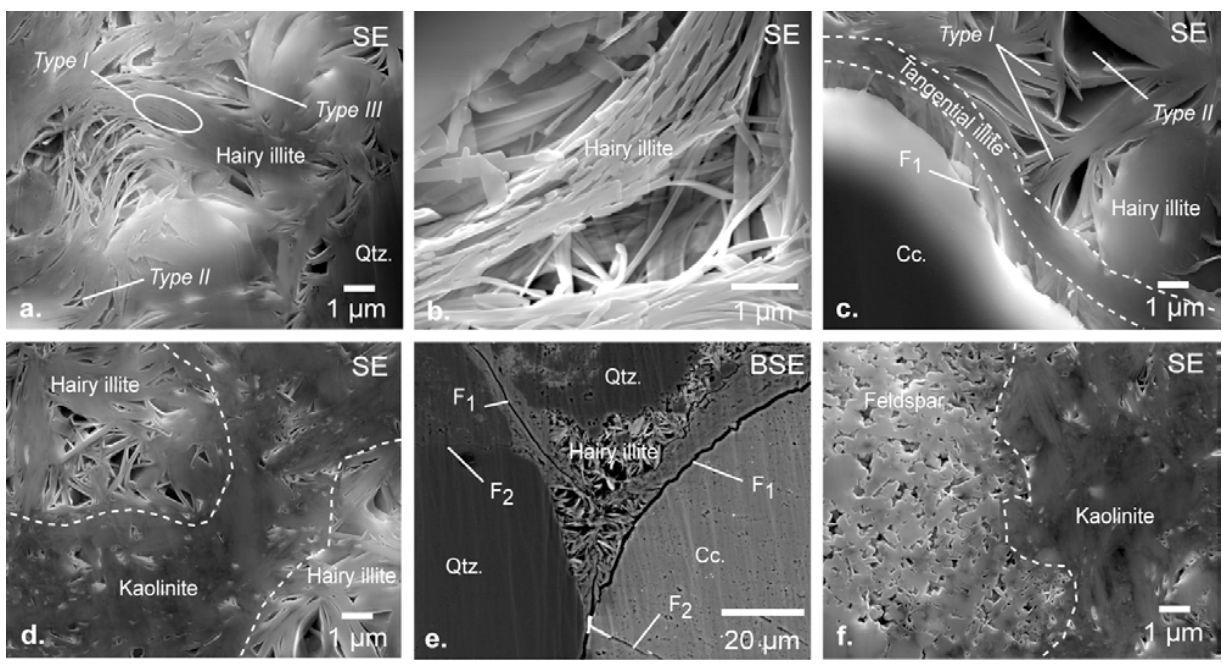

Fig. 3: SEM micrographs (SE and BSE) of typical porous phases revealed by BIB cross sectioning. (a) Hairy illite exhibiting the 3 main types of pore morphology in illite cementation (see text for details). (b) Detail of hairy illite with typical thickness less than $50 \mathrm{~nm}$. (c) Contact between calcite grain (Cc.), tangential illite and hairy illite. Tangential illite is not porous at this scale while hairy illite present here pores corresponding to Type I and Type II. $F_{1}$ fracture was propagated along the calcite-tangential illite contact. (d) Coexistence of hairy illite and kaolinite. The kaolinite region is much less porous than the hairy illite region. (e) Quart-Calcite triple junction with edges coated by tangential illite and filled with hairy illite. Intercrystalline ( $\left.\mathrm{F}_{1}\right)$ and intracrystalline $\left(\mathrm{F}_{2}\right)$ fractures are visible. (f) Contact between porous feldspar and kaolinite. Feldspar exhibits typical pseudo-cubic shaped pores.

Detrital minerals such quartz, feldspar and calcite (Figure 2.2 and 3.e,f) show also evidence of intra-crystalline porosity. Feldspars commonly exhibit intra-crystalline porosity with the pores having a pseudo-cubic morphology, which appears to be controlled by the crystal lattice. They are homogeneously distributed and have a range size of $200-500 \mathrm{~nm}$. Pores in calcite and quartz are rare, and occur as small rounded holes of around $500 \mathrm{~nm}$ in diameter, interpreted to be fluid inclusions cut by the ion beam. Some larger pores (up to few $\mu \mathrm{m}$ ) also occur with more jagged morphology and are filled with visible hairy/fibrous illite.

The sample is significantly fractured (Figures 2.a,b and 3.c,e). Two kinds of fractures are identified. Both are open and uncemented. The first set of fractures $\left(\mathrm{F}_{1}\right)$ occurs at the boundaries of clastic grains, either in the clay cement (figures 3.e) or cutting the clay-clastic grain contact. $\mathrm{F}_{1}$-fractures have jagged-walls. Segmentation of the $\mathrm{F}_{1}$-fracture network and analysis using Image $\mathrm{J} 1.38 \mathrm{x}$ ([14]) show that these fractures represent $1-2 \%$ of the total polished cross-section. The second set of fractures $\left(\mathrm{F}_{2}\right)$ is located within the clastic grains, with straight walls and abutting against other fractures. $\mathrm{F}_{2}$-fractures comprise $1-2 \%$ of the total polished area. Thus, the porosity in $\left(\mathrm{F}_{1}+\right.$ $\mathrm{F}_{2}$ ) is estimated equal to $2-4 \%$ of the total polished cross-section. The morphology of $\mathrm{F}_{1}$-fractures indicates that these fractures are late and were formed by relaxation of stress (from over $200 \mathrm{MPa}$ to atmospheric) after drilling by core damage ([15]). Although intracrystalline fracturing in sandstones due to compaction is a common process ([16]), the $\mathrm{F}_{2}$-fractures are not compatible with the burial history because they are free of cementation or pressure solution. This indicates that $\mathrm{F}_{2}$-fractures have also formed late by core damage ([15], [17]). Core damage is a common problem when evaluating reservoir porosity and correction for core damage is an as yet unsolved question. Using the technique presented here, the porosity due to core damage can be quantified by image analysis.

In many sedimentary basins, illite is present in shales but also in sandstones where it occurs as detrital matrix and as diagenetic cement. Diagenetic illite forms after burial to significant depth ([13], [18]). Illite growth is a major factor in reducing the porosity and permeability of reservoir rocks ([19], [20], [21]) and it causes major problems during (enhanced) recovery ([22]). Until now, direct 
quantitative analysis of the morphology of illite cement and its effect on permeability ([12]) has been difficult, mostly because of the lack of a technique of high-resolution petrography, allowing to prepare 2D cross sections and 3D models of porosity.

In our samples, illite cementation reduces the porosity in triple junctions by more than $60 \%$ (Figure 4). According to [23] Illite arranged tangential to the grain surfaces has less effect on permeability than perpendicular clay minerals; and fibrous illite has a lesser effect in reducing porosity than platy illite. In our samples, tangential illite is compact and has very low porosity; in contrast, porosity in "huggermugger"/hairy illite is much higher and highly connected. In addition, statistical investigations of porosity in triple junction (Figure 4) show that more than $70 \%$ of porosity is due to the contribution of the "hugger-mugger"/hairy illite.

\subsection{Estimation of bulk porosity from detailed investigations at pore scale}

Based on observations of more than 50 positions in the sample, the different types of porosity as classified in section 3.2 are very similar in all studied positions. Therefore, a detailed study of characteristic positions (example of triple junction in Figure 4), is presented as representative for each type of porosity (Figure 5).

Kaolinite typically has a porosity of $5 \%$ and a pore size of 0.8 micron, feldspars have a porosity of $16 \%$ and a pore size of 1.3 micron. Quartz and Calcite are assumed non-porous and we neglected other minor regions known to occur in the sample. At typical narrow grain-grain contacts (Figure 2.c), the tangential illite has low porosity at the resolution of SEM $(<1 \%)$ and could be neglected in comparison to the hairy/fibrous illite bearing $24 \%$ porosity and pores around 1.3 micron. In hairy/fibrous illite, pores have elongated shape (axial ratio greater than 2). The shape of pores is individually controlled by the type of contact between the adjacent clay aggregates forming pores of type I, II or III as described in the section 3.2. At characteristic triple junction (Figure 4), total porosity is about $33 \%$. Here, illite is organized tangentially at edges developing more and more hairy towards the center of the triple junction. Between these two end-members, illite trends to become hairy by bending its tangential organization according to the curvature of the quartz edges forming the triple junction. This gradual development of illite microstructures is observed and quantified by the systematic increasing of the mean pore size and the total porosity contribution towards the center (Figure 4). This analysis gives a first impression of the complex micro-porosity in such tight gas sandstone (Figure 5).

Point counting performed on optical thin section shows that the studied sample consists mainly of quartz $(60 \%)$, calcite $(8 \%)$, feldspars $(7 \%)$, kaolinite $(4 \%)$, illite cementation at narrow grain-grain contacts $(7 \%)$, big pores at triple junction cemented by illite $(10 \%)$ and fractures (average of $3 \%$, see section 3.2 ).

Therefore, combining pore scale porosity measured for each characteristic region with the area fraction of each of these regions, we are able to estimate the total porosity in the core plug. Our estimated total porosity $(9.3 \%)$ is in very good agreement with the bulk porosity $(9.0 \%)$, measured on a core plug of about $10 \mathrm{~cm}^{3}$.

Thus, this approach has the potential for a new procedure for porosity investigation in tight gas sandstones by bridging the information based on porosity at pore scale with macro-scale porosity properties.
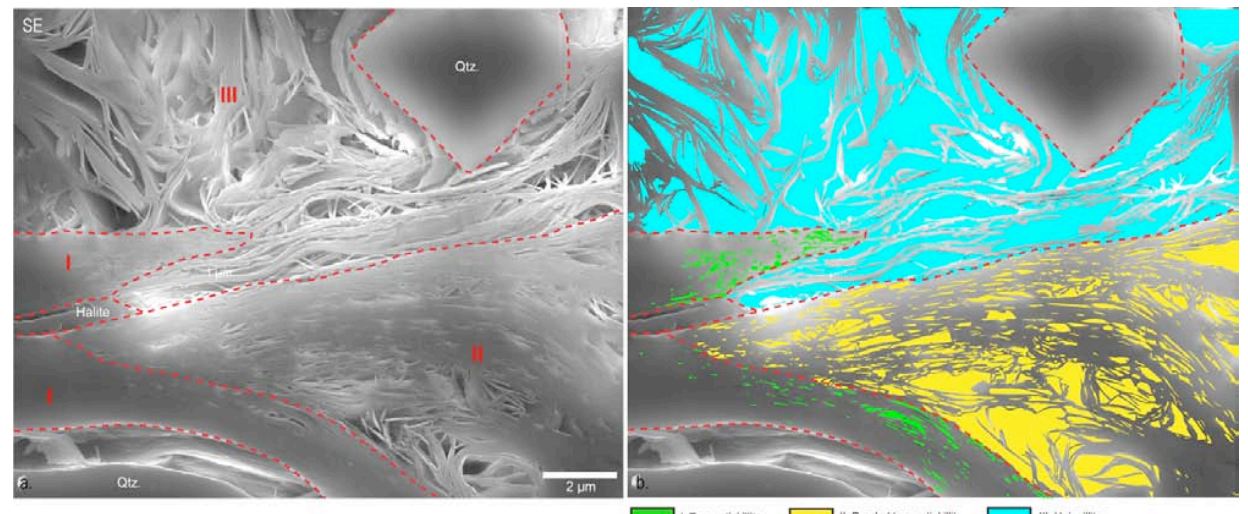

Fig. 4: Quantification of porosity and its morphological evolution into a typical triple junction region partially cemented by illite and floating angular quartz fragment. Illite becomes much more porous towards the center of the pore until it developed a pronounced hairy fabric. (a) SEM image of the investigated area. Three regions are distinguished by dashed red outline: (I) Tangential illite, (II) bended tangential illite and (III) "huggermugger"/hairy illite. (b) Segmented porosity as it appears in (a) used to measure characteristic triple junction porosity. Each typical region is encoded by a different color (see legend). 


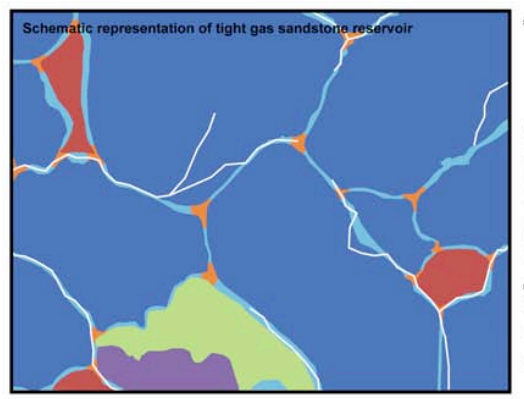

\begin{tabular}{|c|c|c|c|c|c|}
\hline Region & $\begin{array}{c}\text { Amount }^{1} \\
(\%)\end{array}$ & $\begin{array}{c}\text { Porosity }{ }^{2} \\
(\%)\end{array}$ & $\begin{array}{l}\text { Contribution to } \\
\text { total porosity } \\
(\%)\end{array}$ & $\begin{array}{c}\text { Bulk } \\
\text { porosity } \\
(\%)\end{array}$ & $\begin{array}{c}\text { Estimated } \\
\text { total porosity } \\
(\%)\end{array}$ \\
\hline Quartz & 60 & 0 & 0.00 & & \\
\hline Calcite & 8 & 0 & 0.00 & & \\
\hline Feldspar & 7 & 16.22 & 1.14 & & \\
\hline Kaolinite & 4 & 4.93 & 0.20 & 9.0 & 9.3 \\
\hline Illite at narrow contacts & 7 & 24.02 & 1.68 & & \\
\hline Illite in triple junctions & 10 & 32.65 & 3.27 & & \\
\hline Fractures & 3 & 100 & 3.00 & & \\
\hline
\end{tabular}

${ }^{1}$ Average inferred from optical thin-sections

${ }^{2}$ Inferred from porosity statistics performed in our samples (see fiqure 4)

${ }^{3}$ measured porosity from drill-core, no overburden correction

Fig. 5: Estimation of bulk porosity. (left) Schematic representation of the studied tight gas sandstone reservoir showing significant regions taken into account to estimate the bulk porosity from detailed porosity investigations at pore-scale. (Table) Results from quantitative analysis of pore-scale porosity for each relevant phases shown on the left. Combining pore-scale porosity measured for each characteristic region with the area fraction of each of these regions, we are able to estimate the total porosity in the core plug.

\section{Conclusions}

EDX micro-chemical analysis ([24]) and SEM microscopy ([12]) are the usual techniques to investigate tight gas sands. The innovation of our approach is the use of an Argon Broad Ion Beam (Arg-BIB) milling tool to prepare the sample surfaces. Until now, the Arg-BIB preparation technique was mainly used for metallogenic materials but not for polyphase geomaterials. On the one hand, because it does not induce mechanical polishing, the Arg-BIB technique is an alternative to the resin embedment technique for preparation of delicate samples like sandstone, which is difficult to polish because it combines phases with different hardness. In addition, the relatively large area which can be polished (up to $2 \mathrm{~mm}^{2}$, large in comparison to the micro-porosity investigated) by the Arg-BIB allows investigating numerous features in one cross-section and also allows quantitative analysis ([25]), which is very difficult when broken samples surfaces are investigated. Arg-BIB cross sectioning does not require water or epoxy impregnation, which could damage the clay minerals by rewetting. Thus, the Ar-beam polishing technique provides damage-free, reproducible and efficient surface preparation in comparison to the conventional preparation techniques.

Focussed Ion Beam (FIB) technique was also demonstrated to be able to prepare high quality polished cross-sections in clay-rich geomaterials ([4], [6]). However, this technique induces potentially more damage to the surface since it uses mainly Gallium source ([7]) and typical areas produced by FIB (about $\mu \mathrm{m}^{2}$ ) are much smaller than those prepared by BIB (about $\mathrm{mm}^{2}$ ).

Thus, the combination of Ar-BIB and SEM facilities provides an efficient method to get a direct access to porosity and allowing its detailed understanding. It offers the basis for a fundamental understanding of pore geometry, fluid flow, and, in combination with cryogenic techniques ([3], [4]) should be able to offer insight into the geometry and wetting characteristics of in-situ fluid phases in sandstone reservoirs. For industry purposes this approach should yield to an optimized frac planning to reduce possible formation damages and therefore skin effects.

\section{Acknowledgement}

We thank Wintershall Holding AG for help with obtaining the Rotliegend sandstone samples. We are grateful to Alexander Schwedt (GFE at RWTH, Aachen University, Aachen, Germany) for their technical support for the SEM imaging, Werner Krauss and Christian Diebel for the preparation of the samples and Katharina Albert, Jochen Hürtgen and Prokop Zavada for image processing. This project was funded by the Deutsche Forschungsgemeinschaft (UR 64/9-2).

\section{References}

1. B. Lanson, D. Beaufort, G. Berger, A., Bauer A. Cassagnabère and A. Meunier, Clays mineral, 37, 1-22 (2002)

2. R. Schöner and R. Gaupp, International Journal of Earth Sciences, 94, 897-916 (2005).

3. G. Desbois, J.L. Urai, C. Burkhardt, M.R. Drury, M. Hayles, and B. Humbel, Geofluids, 8, 60-72 (2008)

4. G. Desbois, J.L. Urai and P.A. Kukla, e-Earth, 4, 1-8 (2009)

5. D.A.M. De Winter, C.T.W.M. Schneijdenberg, M.N. Lebbink, B. Lich, A.J. Verkleij, M.R. Drury and B.M. Humbel, Journal of Microscopy - Oxford, 233, 372-383 (2009)

6. L. Holzer, Ph. Gasser, A. Kaech, M. Wegmann, A. Zingg, R. Wepf and B. Münch, Journal of Microscopy, 227, $216-228$ (2007)

7. N. Erdmann, R. Campbell and S. Asahina, Microscopy today, May, 22-25 (2006)

8. O. Lexa, P. Štípská, K. Schulmann, L. Baratoux and A. Kröner, Journal of Metamorphic Geology, 23, $649-666$ (2005) 
9. R. Gaupp, A. Matter, J. Platt, K. Ramseyer and J.P. Walzebuck, AAPG Bulletin, 77, 1111-1128 (1993)

10. R. Gaupp, Zbl. Geol. Paläont., teil 1, 1994, 1183-1199 (1996)

11. R. Schöner, Comparison of Rotliegend sandstone diagenesis from the northern and southern margin of the north german basin, and implications for the importance of organic maturation and migration (PhD thesis, Friedrich-Schiller University, Jena, Germany, $160 \mathrm{p}, 2006)$

12. K. Ziegler, Clay minerals, 41, 355-393 (2006)

13. L. Macchi, Geological Journal, 22, 333-345 (1987)

14. M.D. Abramoff, P.J. Magelhaes and S.J. Ram, Biophotonics, International, 11, 36-42 (2004)

15. R.M. Holt, M. Brignoli, E. Fjaer, T.E. Unander and C.J. Kenter. Proc. SPE/ISRM Rock mechanics in petroleum engineering (SPE 28027, Delft, The Netherlands, Balkena, Rotterdam, 55-62, 1994)

16. J.S. Chester, S.C. Lenz, F.M. Chester and R.A. Lang. Earth and Planetary Sciences Letters, 220, 435-451 (2004)

17. B. Haimson, International journal of rock mechanics \& mining sciences, 44,157-173 (2007)

18. R. Schöner, V. Lüders, R. Ondrak, R. Gaupp and P. Möller. Dynamics of Complex Intracontinental Basins - The Central European Basin System, (1-12, 2008)

19. P.J. Stadler, Geologie en Mijnbouw, 53, 217-220 (1973)

20. U. Seeman, Journal of Petroleum Geology, 1, 55-62 (1979)

21. J.D. Kantorowicz, Marine and Petroleum Geology, 7, 66-74 (1990)

22. J.D. Kantorowicz, L. Lievaart, J.G.R. Eylander and M.R.P. Eigne,. Clay Minerals, 21, 769-780 (1986)

23. T.P. Bushell. Habitat of Palaeozoic Gas in N.W. Europe (Special Publication of the Geological Society, London, 23,189-208, 1986)

24. S. Baraka-Lokmane, I.G Main, B.T. Ngwenya and S.C. Elphick, Marine and Petroleum Geology, 26, 39-56 (2009)

25. E.E. Underwood, Quantitative stereology (Addison-Wesley, Reading, Massachusetts, 1970) 